\section{Non-organic visual loss in children}

\begin{abstract}
Background Patients with non-organic visual loss (NOVL) can take up a disproportionate amount of clinic time and clinicians often resort to expensive and prolonged investigations to ensure the correct diagnosis. This is especially the case in children. Methods The case notes of 30 children (18 girls, 12 boys) were retrospectively reviewed following presentation with a primary complaint of visual impairment and a diagnosis of non-organic visual loss. This figure represents $1 \%$ of new paediatric referrals to our unit. Associated symptoms included headache, periorbital pain, diplopia, photopsia and photophobia. Visual field defects were present in $\mathbf{5}$ patients and spasm of the near reflex in 1 child.

Results Treatment consisted of reassurance and was associated with recovery of normal visual function in all cases. Three children were referred to other health care professionals. All psychophysical, electrophysiological and neuroradiological investigations were negative.

Conclusion Our study shows that non-organic visual loss is relatively common in prepubertal children and that this condition can be safely diagnosed using standard clinical tests in the majority of cases. Prompt diagnosis prevents unnecessary investigations and prolonged 'disease' course. Coexisting social conflict was common and may be a contributory factor. Careful explanation and reassurance to both the child and parents remains the mainstay of management.
\end{abstract}

K.E. Bain

S. Beatty

C. Lloyd

Manchester Royal Eye

Hospital

Manchester, UK

Karen E. Bain

Manchester Royal Eye

Hospital

Oxford Road

Manchester M13 9WH, UK

Tel: +44 (0)161 2761234

e-mail:

k.e.bain@ukgateway.net

Received: 13 October 1999 Accepted in revised form:

21 March 2000
KAREN E. BAIN, STEPHEN BEATTY, CHRIS LLOYD

We report on the presenting features, diagnosis, management and visual outcome of 30 patients, all under 16 years of age, with a diagnosis of NOVL.

\section{Methods}

This was a retrospective study of all patients under 16 years of age diagnosed with functional visual loss in the paediatric ophthalmology clinics of one consultant (I.C.L.) in Manchester Royal Eye Hospital between October 1995 and June 1999. Included in this group were children with coexisting ocular pathology but a demonstrable functional overlay.

Non-organic visual loss was a clinical diagnosis. Each patient underwent a thorough orthoptic evaluation and a full ophthalmic examination including fundoscopy. In cases where reduced acuity was alleged but NOVL suspected, an attempt to improve the vision with well-established clinical tests, such as neutralising lenses, was routinely made. This was done by the orthoptist, prior to the ophthalmic consultation. Where indicated, further investigations were undertaken in the form of electrophysiology, psychophysical testing and neuro-imaging. Ultimately the ophthalmologist proved to his or her satisfaction that the alleged symptoms could not be attributed to demonstrable pathology.

\section{Results}

Table 1 summarises the clinical findings at the initial and final examinations. A total of 30 patients under 16 years of age were identified as having functional visual loss. The age range was 6-15 years of age with a mean of 10 years. There were 18 girls and 12 boys. Sources of referral included optometrists $(19,63 \%)$, general practitioners $(3,10 \%)$, other ophthalmologists $(4,13 \%)$, paediatricians $(2,7 \%)$ and selfpresentation via casualty $(2,7 \%)$.

Twenty-eight patients (93\%) complained of reduced or blurred vision at presentation and $2(7 \%)$ reported reduced acuity in conjunction with other visual symptoms. Alleged acuity was less than $6 / 60$ in 3 cases $(10 \%)$ and between $6 / 60$ and $6 / 12$ in 16 cases (53\%). The visual symptoms were bilateral in 25 cases $(83 \%)$. 
Table 1. Clinical findings at the initial and final examinations

\begin{tabular}{|c|c|c|c|c|c|c|}
\hline Patient no. & Age (years) & Sex & Symptoms & Initial acuity & Fields & Final acuity \\
\hline 1 & 13 & $\mathrm{~F}$ & Blurred vision & $6 / 18 \mathrm{R}, 6 / 12 \mathrm{~L}$ & Constricted & $6 / 5 \mathrm{R}, 6 / 5 \mathrm{~L}$ \\
\hline 2 & 6 & $\mathrm{~F}$ & Blurred vision & $6 / 24 \mathrm{R}, 6 / 18 \mathrm{~L}$ & Not noted & $6 / 6 \mathrm{R}, 6 / 6 \mathrm{~L}$ \\
\hline 3 & 8 & $\mathrm{~F}$ & Blurring R eye & $6 / 60 \mathrm{R}, 6 / 6 \mathrm{~L}$ & Cloverleaf & $6 / 6 \mathrm{R}, 6 / 6 \mathrm{~L}$ \\
\hline 4 & 10 & $\mathrm{~F}$ & Blurred vision & $6 / 18 \mathrm{R}, 6 / 18 \mathrm{~L}$ & Normal & $6 / 5 \mathrm{R}, 6 / 5 \mathrm{~L}$ \\
\hline 5 & 10 & $\mathrm{~F}$ & Double vision & $6 / 6 \mathrm{R}, 6 / 9 \mathrm{~L}$ & Not noted & $6 / 6 \mathrm{R}, 6 / 6 \mathrm{~L}$ \\
\hline 6 & 10 & $\mathrm{~F}$ & Blurred vision & $6 / 9 \mathrm{R}, 6 / 9 \mathrm{~L}$ & Normal & $6 / 6 \mathrm{R}, 6 / 5 \mathrm{~L}$ \\
\hline 7 & 10 & M & Optician found blurred vision & $6 / 18 \mathrm{R}, 6 / 12 \mathrm{~L}$ & Normal & $6 / 6 \mathrm{R}, 6 / 6 \mathrm{~L}$ \\
\hline 8 & 11 & $\mathrm{~F}$ & Blurred vision & $6 / 5 \mathrm{R}, 6 / 5 \mathrm{~L}$ & Not noted & $6 / 5 \mathrm{R}, 6 / 5 \mathrm{~L}$ \\
\hline 9 & 12 & $\mathrm{M}$ & Blurred vision & $6 / 36 \mathrm{R}, 6 / 60 \mathrm{~L}$ & Constricted & $6 / 6 \mathrm{R}, 6 / 6 \mathrm{~L}$ \\
\hline 10 & 12 & $\mathrm{~F}$ & Sudden blurring & 6/9 R, HM L & Normal & $6 / 4 \mathrm{R}, 6 / 4 \mathrm{~L}$ \\
\hline 11 & 12 & $\mathrm{M}$ & Blurring R & $6 / 18 \mathrm{R}, \mathrm{PL} \mathrm{L}$ & Not noted & 6/6 R, PL L \\
\hline 12 & 12 & $\mathrm{M}$ & Variable vision & $6 / 24 \mathrm{R}, 6 / 12 \mathrm{~L}$ & Normal & $6 / 6 \mathrm{R}, 6 / 6 \mathrm{~L}$ \\
\hline 13 & 13 & $\mathrm{M}$ & Blurred vision & $6 / 9 \mathrm{R}, 6 / 9 \mathrm{~L}$ & Constricted & $6 / 5 \mathrm{R}, 6 / 4 \mathrm{~L}$ \\
\hline 14 & 13 & $\mathrm{~F}$ & Blurred vision & $6 / 36 \mathrm{R}, 6 / 36 \mathrm{~L}$ & Normal & $6 / 5 \mathrm{R}, 6 / 5 \mathrm{~L}$ \\
\hline 15 & 13 & M & Blurred vision & $6 / 36 \mathrm{R}, 6 / 24 \mathrm{~L}$ & Normal & $6 / 6 \mathrm{R}, 6 / 6 \mathrm{~L}$ \\
\hline 16 & 13 & $\mathrm{M}$ & Failed school VA test & $6 / 9 \mathrm{R}, 6 / 9 \mathrm{~L}$ & Not noted & $6 / 5 \mathrm{R}, 6 / 5 \mathrm{~L}$ \\
\hline 17 & 15 & $\mathrm{~F}$ & Blurred vision & $6 / 18 \mathrm{R}, 6 / 18 \mathrm{~L}$ & Normal & $6 / 6 \mathrm{R}, 6 / 6 \mathrm{~L}$ \\
\hline 18 & 6 & M & Sudden blurring & $6 / 6 \mathrm{R}, 6 / 6 \mathrm{~L}$ & Normal & $6 / 6 \mathrm{R}, 6 / 6 \mathrm{~L}$ \\
\hline 19 & 6 & $\mathrm{~F}$ & Sudden blurring & $2 / 60 \mathrm{R}, 6 / 5 \mathrm{~L}$ & Not noted & $6 / 6 \mathrm{R}, 6 / 6 \mathrm{~L}$ \\
\hline 20 & 7 & $\mathrm{~F}$ & Blurred vision & $6 / 18 \mathrm{R}, 6 / 18 \mathrm{~L}$ & Not noted & $6 / 6 \mathrm{R}, 6 / 6 \mathrm{~L}$ \\
\hline 21 & 8 & $\mathrm{M}$ & Optician found reduced vision & $6 / 12 \mathrm{R}, 6 / 9 \mathrm{~L}$ & Not noted & $6 / 9 \mathrm{R}, 6 / 5 \mathrm{~L}$ \\
\hline 22 & 8 & $\mathrm{~F}$ & Blurred vision & $6 / 18 \mathrm{R}, 6 / 18 \mathrm{~L}$ & Not noted & $6 / 9 \mathrm{R}, 6 / 9 \mathrm{~L}$ \\
\hline 23 & 8 & $\mathrm{~F}$ & Blurred vision & $6 / 36 \mathrm{R}, 6 / 24 \mathrm{~L}$ & Normal & $6 / 5 \mathrm{R}, 6 / 5 \mathrm{~L}$ \\
\hline 24 & 9 & $\mathrm{~F}$ & Blurred vision & $6 / 36 \mathrm{R}, 6 / 36 \mathrm{~L}$ & Not noted & $6 / 6 \mathrm{R}, 6 / 6 \mathrm{~L}$ \\
\hline 25 & 9 & $\mathrm{M}$ & Convergent squint & $6 / 9 \mathrm{R}, 6 / 12 \mathrm{~L}$ & Normal & $6 / 5 \mathrm{R}, 6 / 5 \mathrm{~L}$ \\
\hline 26 & 9 & M & Difficulty at close work & $6 / 18 \mathrm{R}, 6 / 6 \mathrm{~L}$ & Normal & $6 / 6 \mathrm{R}, 6 / 6 \mathrm{~L}$ \\
\hline 27 & 9 & $\mathrm{~F}$ & Blurred vision & $6 / 24 \mathrm{R}, 6 / 18 \mathrm{~L}$ & Normal & $6 / 4 \mathrm{R}, 6 / 4 \mathrm{~L}$ \\
\hline 28 & 9 & $\mathrm{~F}$ & Blurred vision & $6 / 12 \mathrm{R}, 6 / 12 \mathrm{~L}$ & Not noted & $6 / 6 \mathrm{R}, 6 / 6 \mathrm{~L}$ \\
\hline 29 & 15 & $\mathrm{~F}$ & Blurred vision & $6 / 18 \mathrm{R}, 6 / 12 \mathrm{~L}$ & Constricted & $6 / 4 \mathrm{R}, 6 / 4 \mathrm{~L}$ \\
\hline 30 & 8 & $\mathrm{M}$ & Blurred for blackboard & $6 / 9 \mathrm{R}, 6 / 9 \mathrm{~L}$ & Normal & $6 / 6 \mathrm{R}, 6 / 6 \mathrm{~L}$ \\
\hline
\end{tabular}

Five patients $(17 \%)$ complained of field loss in association with reduced acuity, but none reported field defects in the presence of normal central vision. Patterns of field loss included concentric constriction (4) and cloverleaf-shaped fields (1).

Other symptoms included diplopia or polyopia (5, $17 \%)$, photopsia (1), photophobia (1), alteration of colour vision (1) and difficulty with reading (1). The most common associated complaint was headache, in 13 cases $(43 \%)$.

The duration of alleged symptoms at the time of presentation ranged from 1 day to 3 years (mean 7 months). Referral letters mentioned the following specific diagnoses in 13 cases: optic nerve disease or trauma (4), retinal disease (1), uncorrected refractive error (2), orthoptic disorder (5) and cerebral pathology (1).

Twenty-one patients $(70 \%)$ were shown to have $6 / 6$ or better vision at the first clinic appointment using techniques such as neutralising lenses (15 cases, $50 \%$ ) or encouragement, bribery with sweets, and time $(5,17 \%)$. Twenty-seven (90\%) had normal stereoacuity at the first visit. Five patients had physiologically inconsistent visual fields. Two patients reported spontaneous improvement of vision at clinic and demonstrated 6/6 acuity without the use of subterfuge.

Six patients $(20 \%)$ underwent investigations in the form of electrophysiology (4), colour vision assessment (5) and neuro-imaging (4). Three of these patients had undergone neuro-imaging prior to referral to our clinic. All these investigations were reported as normal with the exception of one MRI scan, performed in the referring department, which confirmed the presence of a temporal lobe space-occupying lesion. This diagnosis had been made and the lesion surgically excised prior to the onset of NOVL.

Ocular co-morbidity was uncommon among our patients and was seen in only 5 cases (17\%). Coexisting ocular disease included refractive error $(3,10 \%)$, corneal scarring secondary to herpes simplex keratitis with associated amblyopia (1,3\%) and nystagmus secondary to temporal lobe pathology $(1,3 \%)$.

The treatment offered to all patients consisted of careful explanation and reassurance. The diagnosis was discussed with parents alone, and again with the children present. In all cases the excellent prognosis was emphasised.

Eighteen children $(60 \%)$ were diagnosed at the first visit and were not reviewed. Eight had recovered full visual function by a second appointment and were discharged. Four were seen a third time.

At final follow-up all patients had an acuity of $6 / 9$ or better in both eyes, except for one child with unilateral reduced acuity secondary to corneal scarring. Only one patient reported persistence of her symptoms at review. Three cases were referred to another health care professional: a psychiatrist, a neurologist for persistent headaches and an educational psychologist.

Eighteen of our patients $(60 \%)$ admitted to concurrent social problems, either at home or in the school. Impending exams, bullying, recent change of school and difficulties with schoolwork were cited as possible causative factors by the patients or their parents. Parental 
separation or divorce and subsequent changes of family composition were mentioned in 5 cases $(17 \%)$. One child had stayed with several different foster families over a period of 6 months. In none of our patients was sexual or physical abuse suspected. Four children (13\%) had relatives or friends with spectacle correction or had expressed a desire to wear glasses prior to developing the alleged visual impairment

\section{Discussion}

Our series of 30 children shows a gender bias with a female to male ratio of $1.5: 1$ and a cluster in the 8-13 year age group ${ }^{1-4}$ which concurs with previous studies. The level of alleged visual loss was moderate $(6 / 12$ to $6 / 36)$, and bilateral visual involvement was reported in the vast majority $(83 \%)$. This is also consistent with previous work. ${ }^{1-4}$ Sixty-three per cent of our cases were referred by their optometrist, in contrast to $12 \%$ of our new paediatric referrals in a standard calendar month. This reflects the prominent role of the optometrist in initial care of a child with blurred vision, and the high rate of secondary as well as tertiary referrals within our hospital.

The majority of our patients were shown to have 6/6 acuity or normal stereoacuity at the first visit. As a comprehensive orthoptic assessment, including use of neutralising lenses, is done routinely for any patient suspected of having functional visual impairment, the diagnosis of NOVL is made promptly without resorting to unnecessary investigations. The patient and parents can therefore often be reassured on the first paediatric clinic visit, avoiding prolongation of symptoms. All patients subsequently experienced full recovery of normal acuity and resolution of symptoms. None of these patients have, to our knowledge, had recurrent episodes of NOVL.

A high proportion of our patients complained of other symptoms including headaches $(43 \%)$ and ocular or periocular pain $(20 \%)$. All non-visual symptoms had resolved by the time of review. One patient who described diplopia was shown to be voluntarily converging, a well-recognised phenomenon of nonorganic disease. ${ }^{1}$

Visual field defects were not a common complaint among our patients but, interestingly, where seen were typical of NOVL. ${ }^{1,2,4,5,7,8}$ In contrast to other papers reporting on adults, none of our patients exhibited tubular or spiral fields. However, field testing was performed using the Humphrey field analyser or to confrontation, neither of which are ideal in cases of suspected NOVL. ${ }^{7,8}$

Functional overlay in patients with recognised ocular or neuro-ophthalmic disease was seen in 5 patients $(17 \%)$. Although this may make diagnosis of functional visual impairment more difficult, coexisting pathology in cases of NOVL is well described. ${ }^{2,46,9}$ A functional element should therefore always be considered when the level of a subjective response is inconsistent with the established pathology.

Sixty per cent of our patients, or their parents, acknowledged difficulties in the home or school at the time of clinic attendance. This compares with $40 \%$ in the study by Catalano et al. ${ }^{1}$ and $90 \%$ in Keltner's study. ${ }^{4}$ It is possible that sources of conflict in some children may go unrecognised. The difficult home circumstances experienced by one child in our group were not obvious until he was questioned in more detail by a child psychologist. However, it is worth noting that Kathol et al. ${ }^{10}$ found psychiatric consultation in cases of NOVL did not affect the eventual visual outcome. Our study shows there is usually full resolution of symptoms with reassurance alone - findings consistent with other studies. $1,2,6$

NOVL is a relatively common problem in children, especially in the 8-13 year age group, and predominantly affects girls. NOVL can present with a plethora of visual symptoms and the ophthalmologist should therefore be vigilant to the possibility of this diagnosis. However, it should be emphasised that every child with a visual complaint must be presumed to have ocular pathology until proven otherwise. Functional visual impairment is easily demonstrable in the majority of paediatric cases using simple clinical techniques. Prompt diagnosis will prevent unnecessary investigations and follow-up, and will also contribute to a more rapid resolution of the child's symptoms. In children, the visual prognosis of NOVL is usually excellent.

\section{References}

1. Catalano R. Functional visual loss in children. Ophthalmology 1986;93:385-9.

2. Beatty S. Non-organic visual loss. Postgrad Med J 1999;75:201-7.

3. Clarke W. Functional visual loss in children: a common problem with an easy solution. Can J Ophthalmol 1996;31:311-3.

4. Keltner J. The California syndrome: functional visual complaints with potential economic impact. Ophthalmology 1985;92:427-35.

5. Rada R. Visual conversion reaction in children and adults. J Nerv Ment Dis 1978;166:580-7.

6. Rada R. Visual conversion reaction in children. II. Follow up. Psychosomatics 1973;14:271-6.

7. Smith T. Perimetric findings in functional disorders using automated techniques. Ophthalmology 1987;94:1562-6.

8. Stewart J. Automated perimetry and malingerers: can the Humphrey be outwitted? Ophthalmology 1995;102:27-32.

9. Thompson HS. Functional visual loss. Am J Ophthalmol 1985;100:209-13.

10. Kathol RG. Functional visual loss: follow up of 42 cases. Arch Ophthalmol 1983;101:729-35. 